\title{
Caracterização da fauna cavernícola e da flora rupícola da cavidade do Morro Redondo, lúna/ES
}

A equipe de pesquisadores da empresa Helium Corp Engenharia elaborou o inventário bioespeleológico da cavidade do Morro Redondo, localizada na sub-bacia do rio Pardo, no município de lúna localizado na Serra do Caparaó, também foi analisada a sua relevância, segundo a Resolução CONAMA no 347 , de 10 de setembro de 2004 e a Instrução Normativa no 02, de 30 de agosto de 2017. A área de estudos localiza-se no distrito de Nossa Senhora das Graças, na comunidade do Morro Redondo. De acordo com o Centro Nacional de Pesquisa e Conservação de Cavernas (CECAV), a cavidade do Morro Redondo é a única caverna registrada para o município de lúna-ES, no Cadastro Nacional de Informações Espeleológicas (CANIE) até a síntese deste estudo. A cavidade foi topografada e teve seu inventário bioespeleológico realizado, assim como a sua caracterização histórica e cultural, fatores que possibilitaram avaliar a sua relevância. Com a ampliação do número de ocorrências de cavernas para a Serra do Caparaó, será possível uma melhor caracterização do perfil das cavernas desenvolvidas na região de lúna. Portanto, espera-se que a divulgação dessa pesquisa, possa contribuir como base para futuros estudos bioespeleológicos na região.

\section{Cave fauna characterization and the rupícolous flora of the Morro Redondo cavity, lúna/ES}

\begin{abstract}
The team of researchers from the Helium Corp Engenharia company prepared the biospeleological inventory of the Morro Redondo cavity, located in the Pardo River sub-basin, in the municipality of lúna located in the Serra do Caparaó, its relevance was also analyzed, according to CONAMA Resolution no 347 , of 10 September 2004 and Normative Instruction no 02, of 30 August 2017. The study area is located in the district of Nossa Senhora das Graças in the community of Morro Redondo. According to the National Cave Research and Conservation Center (CECAV), the Morro Redondo cavity is the only cave registered for the municipality of lúna-ES in the National Register of Speleological Information (CANIE) until the synthesis of this study. The cavity was topografed and its biospeleological inventory was synthesized as well as its historical and cultural characterization, factors that made it possible to assess its relevance. With the increase in the number of caves occurring to Serra do Caparaó, it will be possible to better characterize the profile of the caves developed in the region of lúna. It is hoped that the dissemination of this research can contribute as a basis for future biospeleological studies in the region.
\end{abstract}

Keywords: Speleological Heritage; Biospeleology; CONAMA Resolution no 347/2004; Normative Instruction no 02/2017; Speleometry.

Topic: Conservação da Biodiversidade

Reviewed anonymously in the process of blind peer.
Received: 19/07/2019

Approved: 15/12/2019
Cleber Vinicius Vitorio da Silva

Fundação Oswaldo Cruz, Brasil

http://lattes.cnpq.br/4275890458575782

http://orcid.org/0000-0001-8337-9615

clebervitorio88@gmail.com

Juan Carlos Resende de Moraes (iD)

Universidade Federal Rural do Rio de Janeiro, Brasil

http://lattes.cnpq.br/2120256098910920

http://orcid.org/0000-0002-8762-2798

resendejcm@gmail.com

Vanessa da Silva Brandão (iD

Universidade Federal Fluminense, Brasil

http://lattes.cnpq.br/8694811494605508

http://orcid.org/0000-0002-1119-212X

vsbrandao@id.uff.br

\author{
Josimar Ribeiro de Almeida (ID) \\ Universidade do Estado do Rio de Janeiro, Brasil \\ http://lattes.cnpq.br/3215586187698472 \\ http://orcid.org/0000-0001-5993-0665 \\ almeida@poli.ufri.br \\ Carlos Eduardo Silva (iD \\ Companhia Brasileira de Produção Científica, Brasil \\ http://lattes.cnpq.br/3700554054159220 \\ http://orcid.org/0000-0001-8358-0263 \\ carlos.eduardo@cbpciencia.com.br
}

Referencing this:

SILVA, C. V. V.; MORAES, J. C. R.; BRANDÃO, V. S.; ALMEIDA, J. R.; SILVA, C. E.. Caracterização da fauna cavernícola e da flora rupícola da cavidade do Morro Redondo, lúna/ES. Naturae, v.1, n.2, p.14-31, 2019. DOI: http://doi.org/10.6008/CBPC2674-6441.2019.002.0002 


\section{INTRODUÇÃO}

Segundo o Grupo Bambuí de Pesquisas Espeleológicas, espeleologia é o estudo das cavernas, de sua gênese e evolução, do meio físico que elas representam, de seu povoamento biológico atual ou passado, bem como dos meios ou técnicas que são próprias ao seu estudo. Essa palavra vem do latim spelaeum (caverna) e do grego logos (estudo). Entre as ciências que se relacionam com a espeleologia estão geologia, geografia, hidrologia, biologia, climatologia e arqueologia (BRANDI, 2012).

Segundo o Decreto no 6.640, de 07 de novembro de 2008, "cavidade natural subterrânea" é todo e qualquer espaço subterrâneo acessível pelo ser humano, com ou sem abertura identificada, popularmente conhecido como caverna, gruta, lapa, toca, abismo, furna ou buraco, incluindo seu ambiente, conteúdo mineral e hídrico, a fauna e a flora ali encontrados e o corpo rochoso onde os mesmos se inserem, desde que tenham sido formados por processos naturais, independentemente de suas dimensões ou tipo de rocha encaixante. O levantamento feito pela Centro Nacional de Pesquisa e Conservação de Cavernas (CECAV) mostra que o estado do Espírito Santo apresenta 43 cavernas, o que corresponde a 0,21\% do total de cadastros no Brasil, sendo um dos estados menos inventariados em relação ao patrimônio espeleológico (CECAV, 2019).

O Espírito Santo, por ser um estado com ocupação antiga passou por diversos ciclos econômicos de exploração e de produção, no qual seus ecossistemas originais foram sendo progressivamente eliminados e descaracterizados. O Espírito Santo está incluso no domínio da Mata Atlântica. A devastação das florestas nesse estado vem ocorrendo praticamente desde o período do descobrimento, diminuindo drasticamente sua cobertura vegetal original. Da área original resta em torno de 7,26\% (SOS MATA ATLÂNTICA, 2016). A região de lúna, localizada na sub-bacia do rio Pardo, está inserida no bioma Mata Atlântica, com ocorrência de Floresta Ombrófila Densa e Floresta Estacional Semidecidual. Em decorrência do histórico de intenso processo de crescimento econômico nas últimas décadas, o que encontramos hoje nesta região são pequenos fragmentos de vegetação nativa, isolados por extensas áreas de pastagens, lavouras de café e plantios de eucaliptos, restando menos de $10 \%$ da cobertura florestal original (BACKES et al., 2004).

Os ambientes rochosos com presença de uma comunidade vegetal, possuem singular fitofisionomia, dada a diversidade geomorfológica, geológica e a pluralidade climática, distintas comunidades vegetais se inserem nos afloramentos, caracterizando os hábitats saxícolas ou rupícolas. São ambientes marcantes pela escassez de solo e pela fatorialidade edáfica. A vegetação que coloniza a borda de cavidades de ambientes rochosos, possui importância significativa na manutenção do ecossistema cavernícola. Considerando a importância da cobertura vegetal para a preservação das condições microclimáticas e para a manutenção do aporte de detritos orgânicos no interior das cavidades se faz necessária a conservação da vegetação ali existente, bem como a sua caracterização, pois além de essenciais para a manutenção da biodiversidade no interior das cavidades, não é incomum o registro de espécies endêmicas destes ambientes, nunca antes registradas na literatura científica (MEDINA et al., 2006).

No aspecto ecológico os ambientes cavernícolas abrigam ecossistemas e seres vivos com singular 
diversidade. Existe desde a superfície até o interior de uma caverna, uma sucessão de habitats subterrâneos que se apresentam com configurações e espécies diferentes. A fauna cavernícola é comumente classificada em espécies que se enquadram em três grupos: Troglóxenos - são organismos que precisam sair das cavernas para completar seu ciclo de vida, geralmente habitam próximo à zona de entrada das cavidades subterrâneas, como é o caso dos morcegos; Troglófilos - são seres capazes de completar todo o seu ciclo de vida nas cavernas; e Troglóbios - são organismos que tem todo o seu ciclo de vida restrito ao interior das cavernas, habitando as zonas afóticas (sem luz) das cavidades, apresentando características como despigmentação, ausência de olhos e alongamento dos apêndices sensoriais (ICMBio, 2010).

As cavernas representam importante papel para a conservação da biodiversidade, oferecendo ofertas de abrigo, alimento e água para a fauna, e importante lócus de estabelecimento para a flora rupícola, donde encontram-se muitos táxons endêmicos, presentes em listas de ameaça e ainda com um históriconatural de coevolução com espécimes da fauna. A empresa Helium Corp Engenharia realizou o inventário bioespeleológico da cavidade do Morro Redondo, localizada na sub-bacia do rio Pardo, é a única cavidade registrada no CANIE para o município de lúna, até a presente data deste trabalho científico, e também focando no contexto histórico-cultural regional, segundo a Instrução Normativa no 02, de 30 de agosto de 2017 e a Resolução CONAMA no 347, de 10 de setembro de 2004.

\section{MATERIAS E MÉTODOS}

\section{Caracterização da Área de Estudos}

A Cavidade do Morro Redondo (-20.396103/-41.511984) está inserida na área de influência da subbacia do Rio Pardo, na bacia do rio Itapemirim. A área de estudo está localizada no município de lúna, a 192 km do município de Vitória, Espírito Santo, sendo a única caverna registrada no CANIE para o município de lúna. O acesso pode ser realizado através das rodovias BR 484 e ES 379. Esta área foi delimitada segundo a Instrução Normativa no 02/2017 e a Resolução CONAMA n 347/2004, o qual indica que seja contemplado ao menos 250 metros do entorno do Rio Pardo (Figura 1), com 10.3474,37 $\mathrm{m}^{2}$ de área total.

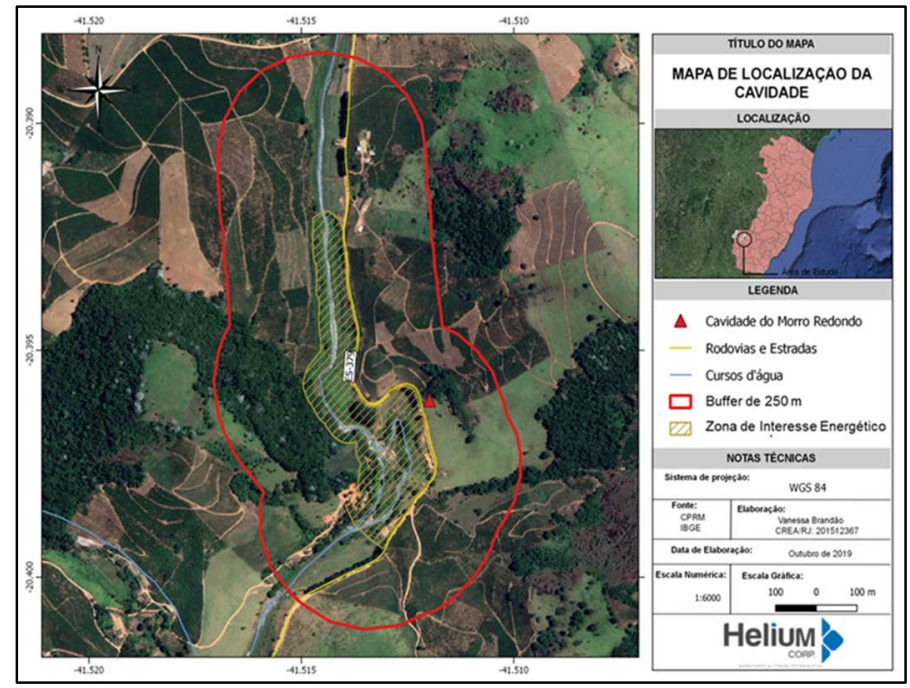

Figura 1: Mapa de localização da área de estudo. 
Antes de atravessar o Município de lúna, o rio Pardo recebe as águas do córrego Boa Vista. A jusante do Município em sua margem direita, ocorre a confluência com outro importante afluente o ribeirão Santo Antônio também com os córregos da Ponte Alta, Vista Alegre e Jatobá, ao passo que na margem esquerda há a confluência os córregos, da Anta, Morro Redondo e o córrego Terra Comprida, a área de estudos localizase na área de influência do córrego do Morro Redondo.

A área de estudo está inserida no Complexo Serra do Valentim, dominado por granulítos básicos, enderbitos, charnockitos e charno-enderbitos (VIEIRA et al., 2018). A área de influência direta (AID) é composta por blocos de gnaisses com porções migmatiticas de cor cinza, grãos de quartzo, granada, biotita e feldspato de tamanho médio a grossa. A porção migmatítica é formada por fenocristais félsicos de composição granítica, com presença de quartzo, plagioclásio e biotita (Figura 2).

A contextualização do ambiente físico da sub-bacia do rio Pardo indicou a presença de lineação de estiramento mineral, além de foliações e sistema de faturamento na região. As rochas gnáissicas se dispõem formando blocos e dão forma a um relevo bastante acentuado e íngreme tanto na AID quanto no entorno em todas as regiões visitadas. Os morros formados tendem a apresentar depósito de tálus em algumas porções mais baixas das encostas.

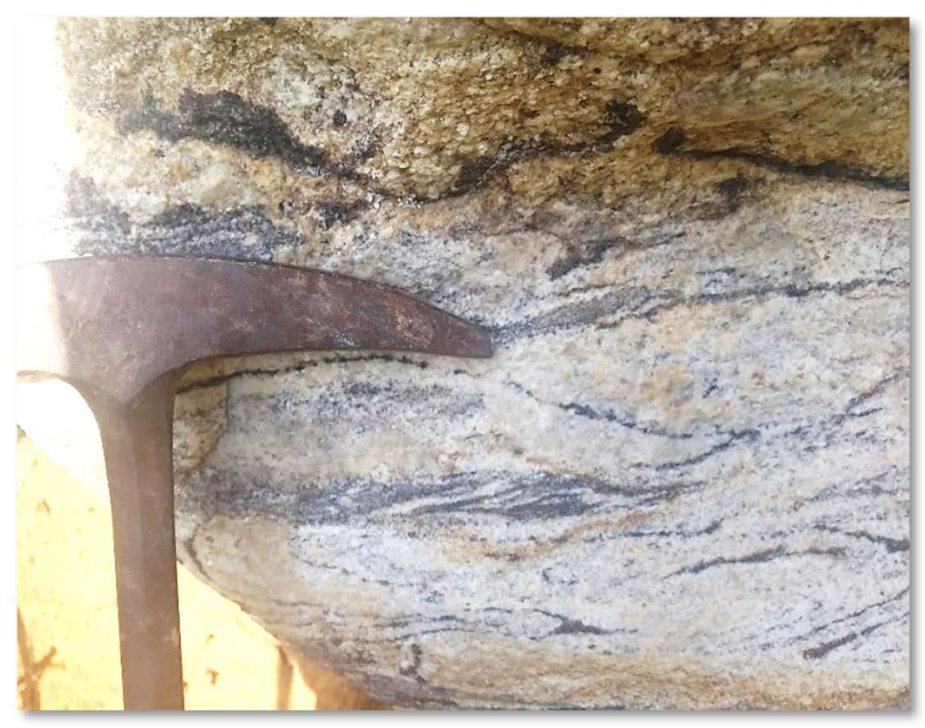

Figura 2: Gnaisse de granulação média a grossa com porção milonítica granítica, com presença de quartzo, plagioclásio e biotita, encontrado na cavidade do Morro Redondo.

A unidade litológica apresenta um forte controle estrutural no relevo, e isso se deve a grande presença de falhas e fraturas na região. Estas falhas e fraturas são marcadas por voçoramento e queda de blocos atrelados ao processo de esfoliação esferoidal em rocha, tudo isso condicionado à sua estrutura, que formam morros e pequenas serras, com declive ondulado a fortemente ondulado.

O relevo é bastante acidentado e homogêneo, o controle estrutural é registrado pela presença de vales e vertentes retilíneos, além do nivelamento de topo. A ação intempérica proporciona o desenvolvimento de um processo sobre as rochas denominado esfoliação esferoidal que tende a originar matacões e grandes blocos com geometrias arredondadas.

No município de lúna são encontrados três diferentes Unidades geomorfológicas: Patamares 
escalonados do sul capixaba, Maciços do Caparaó e acumulação fluvial. A área de influência mapeada está inserida na Unidade geomorfológica Maciços do Caparaó, com relevo dominantemente montanhoso. São formas muito acidentadas, com vertentes predominantemente côncavas e topos de cristas ou levemente arredondados, com depósitos de tálus (Figura 3).

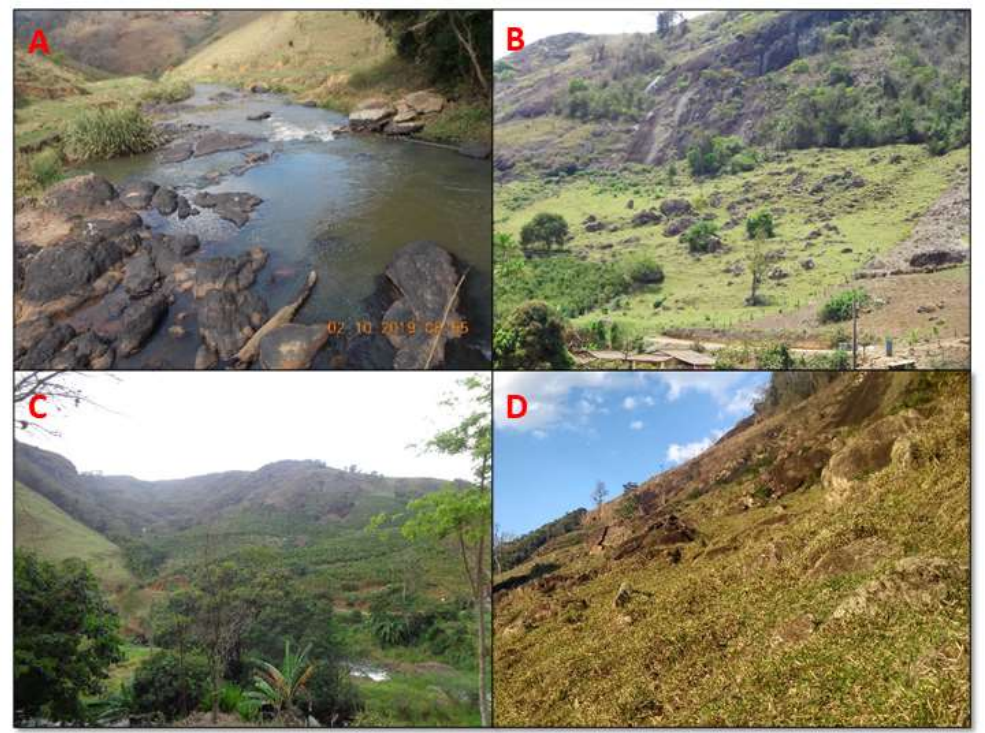

Figura 3: A- Matacões dispostos no leito do Rio Pardo inseridas na AID; B- Afloramento rochoso com presença de blocos e matacões; C- Padrão de relevo montanhoso predominante na área de estudos e entorno; D- Ilustração de vertente com alta declividade e acúmulo de blocos e matacões.

Na sub-bacia do rio Pardo foram identificadas duas Estações Fluviométricas e de Qualidade de Água, conforme segue: Estação lúna - código 57360000 e Estação Terra Comprida Montante - código 57370000. A entidade responsável por estas estações é a ANA - Agência Nacional de Águas, sendo o CPRM - a entidade operadora. No que diz respeito aos principais usos do solo na bacia hidrográfica do rio Pardo, é observável que predominam nesta bacia os Cultivos Agrícola, especialmente a cafeicultura e as Pastagens. Nota-se também a presença, em muito menor proporção, de áreas com Mata Nativa e de Reflorestamentos, além dos aglomerados urbanos referentes às sedes dos municípios de lúna, Ibatiba e Irupi. Na área de estudos os principais fatores de impacto ambiental negativo sobre o rio Pardo são a agricultura, pecuária e a fragmentação da vegetação ciliar, que, em efeito cascata, gera a assoreamento do rio, a elevação da turbidez e a diminuição dos níveis de oxigênio dissolvido. Também é visível que a mata ciliar se encontra descaracterizada, o que impacta diretamente o ecossistema terrestre do entorno do rio, assim como seu ecossistema aquático.

O tipo de solo predominante na bacia hidrográfica do Rio Itapemirim é o Argissolo Vermelho. Os Argissolos Vermelhos se caracterizam pela profundidade variável, com um horizonte subsuperficial com maior teor de argila e a menor condutividade hidráulica que o superficial (ESPÍRITO SANTO, 2008). O município de lúna, apresenta a predominância de solo Cambissolo e uma porção de Latossolo VermelhoAmarelo (ESPÍRITO SANTO, 2008), sendo possível observar estes dois tipos de solo para a área de influência do empreendimento.

O local de estudo apresenta um clima quente e temperado. Há muito mais pluviosidade no verão que 
no inverno. O clima é classificado como Cwa segundo a Köppen e Geiger. A temperatura média em lúna é de $20,5^{\circ} \mathrm{C}$. Há pluviosidade média anual de $1253 \mathrm{~mm}$. O mês mais seco é junho, com $21 \mathrm{~mm}$ de precipitação. $\mathrm{O}$ mês de dezembro é o mês com maior precipitação, apresentando uma média de $218 \mathrm{~mm}$. O mês mais quente do ano é janeiro, com uma temperatura média de $23,3{ }^{\circ} \mathrm{C}$. Ao longo do ano, junho tem uma temperatura média de $17,4^{\circ} \mathrm{C}$, sendo a temperatura média mais baixa do ano (ANA, 2007).

A região de lúna, localizada na bacia do rio Pardo, está inserida no bioma Mata Atlântica, com ocorrência de Floresta Ombrófila Densa e Floresta Estacional Semidecidual. Em decorrência do histórico de intenso processo de crescimento econômico nas últimas décadas, o que encontramos hoje nesta região são pequenos fragmentos de vegetação nativa, isolados por extensas áreas de pastagens, lavouras e plantios de eucaliptos, restando menos de $10 \%$ da cobertura florestal original (BACKES et al., 2004).

A estrutura e a dinâmica dos remanescentes florestais existentes na bacia estão sendo diretamente afetados por diversos fatores, dentre os quais se destacam o histórico de perturbações antrópicas, o tamanho destas áreas, a sua forma, o estágio de sucessão secundária da vegetação, o tipo de vizinhança, o grau de isolamento e a contaminação dos recursos hídricos, que devem ter comprometido a diversidade biológica e a sustentação destes ambientes naturais. Quanto ao histórico de perturbações antrópicas, observa-se que a maioria das matas remanescentes exibe características típicas da fragmentação florestal, com evidências de queimadas, efeitos de borda e infestação por espécies pioneiras, alóctones e trepadeiras. Estes remanescentes florestais encontram-se entremeados por campos antrópicos, como pastagens e áreas agrícolas, geralmente isolados, com pouca conectividade entre si (Figura 4).

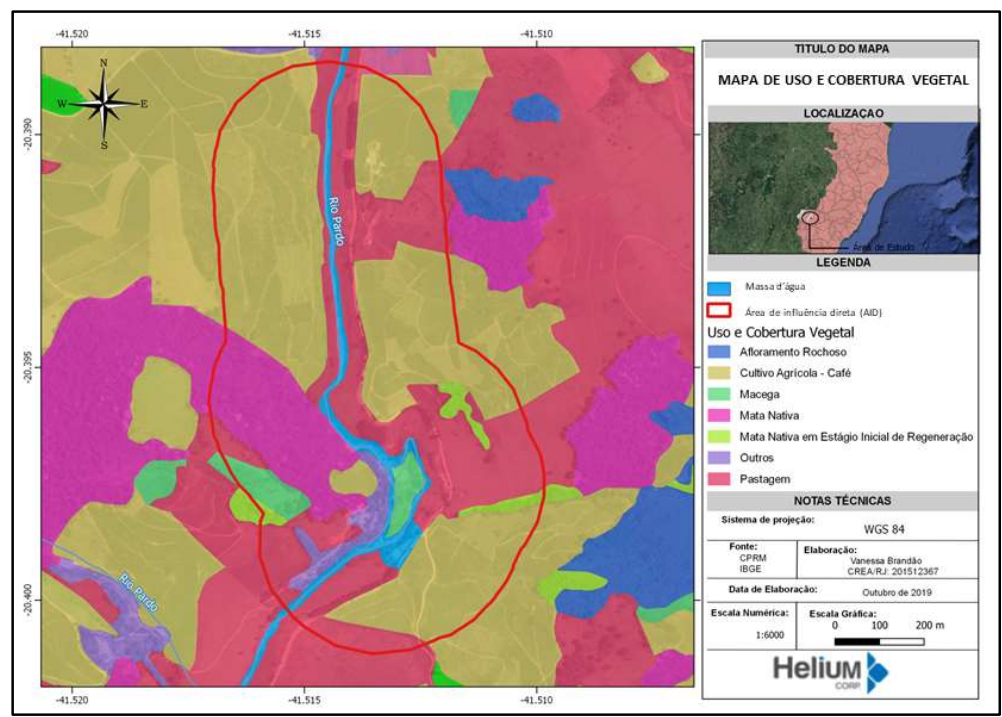

Figura 4: Mapa de uso e cobertura vegetal da área de estudos.

\section{Levantamento espeleométrico}

Durante o mapeamento se utilizou trena, bússola geológica Bruton, clinômetro e GPS - Garmin 62S (sistema de coordenadas UTM, fuso 24K, datum WGS-84). Uma ficha de cadastro foi preenchida contendo descrição geral da cavidade e entorno, além do croqui. O grau de precisão do levantamento topográfico $4 \mathrm{C}$ (DAY, 2002) da British Cave Research Association (BCRA).

Através do mapeamento espeleológico, foram obtidas as variáveis espeleométricas, sendo estas 
fundamentais para a espeleotopografia de cavernas. Para efeito de parâmetros espeleométricos, neste trabalho foi adotado o método de Projeção Horizontal $(\mathrm{PH})$, onde $\mathrm{PH}=(\mathrm{AB}=0)+\mathrm{BC}$ (Figura 8), com o intuito de medir o desenvolvimento da cavidade. Conforme as Normas e Convenções Espeleométricas da Sociedade Brasileira de Espeleologia (1991), esta metodologia consiste em medir a galeria em uma projeção horizontal em planta, como ilustrado na figura 5.

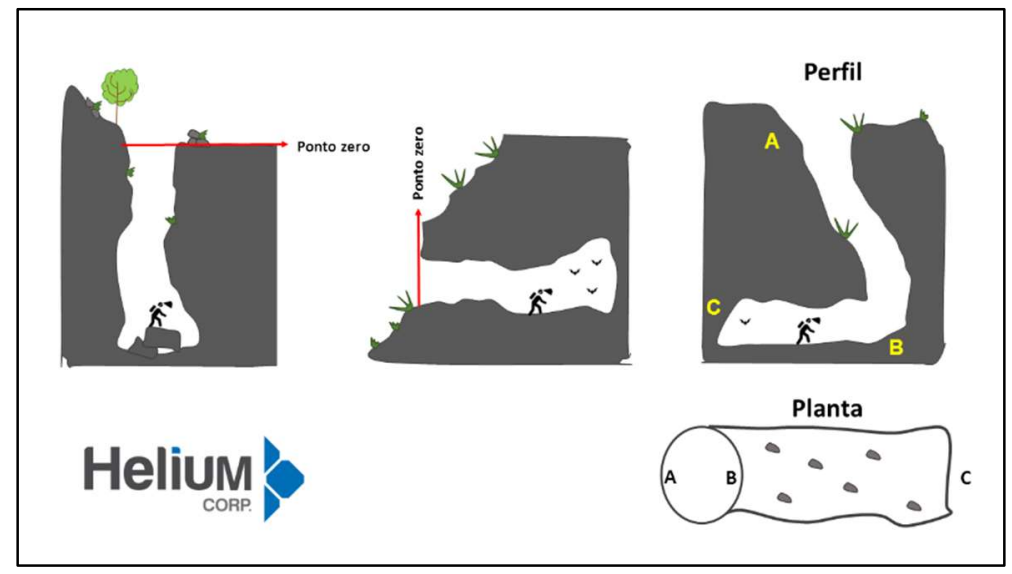

Figura 5: Métodos de cálculo espeleométrico adotados neste trabalho.

O método denominado "desenvolvimento linear" (DL), onde $D L=A B+B C$ (Figura 8), difere da projeção horizontal por ser o somatório das distâncias adquiridas durante as medições na caverna. Normalmente utiliza-se este método para cavidades naturais subterrâneas que apresentem inclinações ou verticalizações, os quais não seriam considerados em uma projeção horizontal. No caso de ocorrência de cavidades horizontais, ambos métodos apresentam o mesmo valor final (CECAV, 2013).

Após a elaboração do Croqui topográfico, através do software Autocad 2009, foi possível constatar o valor da projeção horizontal para a cavidade do Morro Redondo. Posteriormente, foi realizada a análise do meio biótico, físico e social de acordo com a Instrução Normativa no 02 de 30 de agosto de 2017, do Ministério do Meio Ambiente, o qual define a metodologia para a classificação do grau de relevância das cavidades naturais subterrâneas, conforme previsto no art. 50 do Decreto no 99.556 , de 1 으 de outubro de 1990.

\section{Caracterização Ecológica das Cavidades}

No aspecto ecológico os ambientes cavernícolas abrigam ecossistemas e seres vivos com singular diversidade. Existe desde a superfície até o interior de uma caverna, uma sucessão de habitats subterrâneos que se apresentam com configurações e espécies diferentes. A caracterização e relevância espeleológica da área de estudos, foi realizada segundo a Instrução Normativa no 02/2017 e a Resolução CONAMA no 347/2004, que leva em consideração para a relevância e sensibilidade ecológica das cavidades naturais subterrâneas, fatores geoestruturais e singularidades do meio físico que estejam correlacionadas ao ambiente cavernícola, fatores ecológicos e ambientais, isto é, se existem organismos cuja história de vida tenha relação com o ambiente de caverna e fatores culturais e históricos como constatação do uso das cavernas por agrupamentos humanos do passado e do presente, constatação de valor arqueológico e 
paleontológico das cavernas.

Fauna

A fauna cavernícola é comumente classificada em espécies que se enquadram em três grupos: Troglóxenos - são organismos que precisam sair das cavernas para completar seu ciclo de vida, geralmente habitam próximo à zona de entrada das cavidades subterrâneas, como é o caso dos morcegos; Troglófilos são seres capazes de completar todo o seu ciclo de vida nas cavernas; e Troglóbios - são organismos que tem todo o seu ciclo de vida restrito ao interior das cavernas, habitando as zonas afóticas (sem luz) das cavidades, apresentando características como despigmentação, ausência de olhos e alongamento dos apêndices sensoriais (ICMBio, 2010).

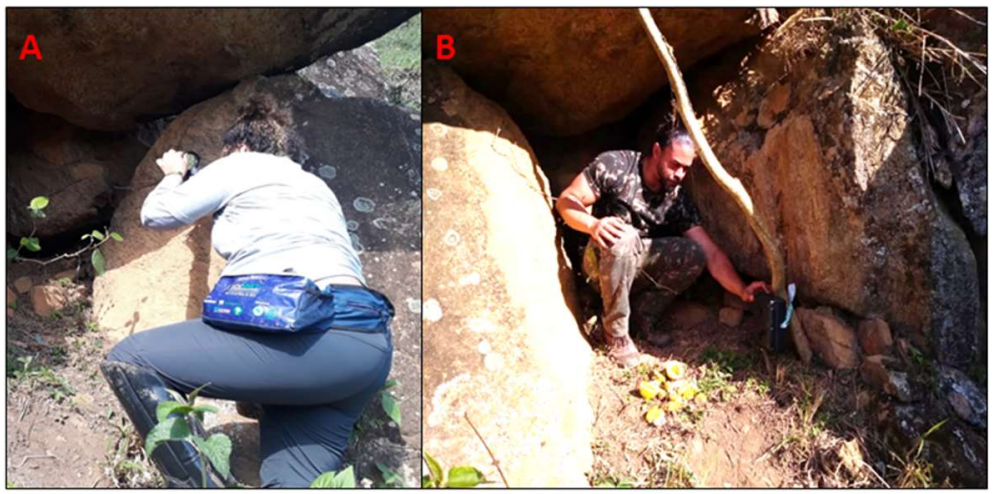

Figura 6: A- Busca ativa por vertebrados e invertebrados no interior de uma cavidade; B- Instalação de câmera trap no interior de uma cavidade.

Durante as atividades de prospecção bioespeleológica (Figura 6), a equipe de campo registrou a colonização da cavidade por vertebrados (mastofauna, herpetofauna e ornitofauna) e invertebrados (entomofauna e araneofauna), foi realizada a metodologia proposta por Vieira et al. (2017), que consiste na busca ativa por fauna na área das cavidades, uma equipe de três pesquisadores percorrendo a pé as áreas delimitadas, inspecionando todos os micro hábitats disponíveis (bromélias, cavidades, pedras, folhiço, troncos caídos, poças, pedras em cursos d'água e vegetação emergente quanto existente) durante um período estabelecido de oito horas diárias, sendo três no período matutino ( $8 \mathrm{~h}$ às $11 \mathrm{~h}$ ), duas horas no período vespertino (15 h às $17 \mathrm{~h}$ ) e outras três no período crepuscular/noturno (18h às $21 \mathrm{~h}$ ) (não considerando o horário de verão). Através deste método foi empreendido um esforço de 8 horas/homem por dia e 24 horas/ por unidade amostral ao dia, as cavidades foram inspecionadas por 3 dias consecutivos, totalizando 72 horas/ por unidade amostral ao todo.

Com a finalidade de incrementar o diagnóstico de biodiversidade das cavidades, fez-se a instalação de uma câmera trap no interior de cada cavidade encontrada. Este é um método não invasivo para registrar mamíferos terrestres de médio e grande porte (SILVA et al., 2017), permitindo ao pesquisador ter acesso constante a presença de animais no ponto onde a armadilha fotográfica foi instalada, com registro do dia e da hora da ocorrência (VIEIRA et al., 2017).

A armadilha fotográfica utilizada consiste em uma câmera fotográfica digital (Figura 9), instalada no interior de uma caixa protegida de umidade e agentes externos, ligada a sensores externos infravermelhos 
ou mecânicos que detectem movimentos e/ou variações térmicas (SILVA et al., 2017). Em frente a ela foram colocadas iscas a fim de aumentar a atratividade e o número de registros dos animais. As iscas consistem em óleo de fígado de bacalhau, bacon, abacaxi, milho, sal grosso, ração de cachorro, sardinha, banana e maçã. A armadilha ficou ativa por dois dias consecutivos, com esforço total de 72 horas de monitoramento.

\section{Flora}

A equipe de campo levantou as espécies botânicas que estivessem colonizando a cavidade do Morro Redondo (Figura 7) através da classificação das formas de vida de RAUNKIAER (1905), aprimorada por CABRERA et al. (1973) e o estudo de SILVA et al. (2018). Foi realizado o censo das espécies que estivessem colonizando um diâmetro de $30 \mathrm{~m}$ para a cavidade do Morro Redondo, este levantamento inclui as formas de vidas (herbácea, liana, árvore, arbusto, trepadeira herbácea). Os indivíduos de porte herbáceo foram coletados e catalogados no herbário do laboratório de plantas forrageiras da Universidade Federal Rural do Estado do Rio de Janeiro - UFRRJ do instituto de zootecnia e os indivíduos de porte arbóreo catalogados na coleção botânica da UFRRJ.

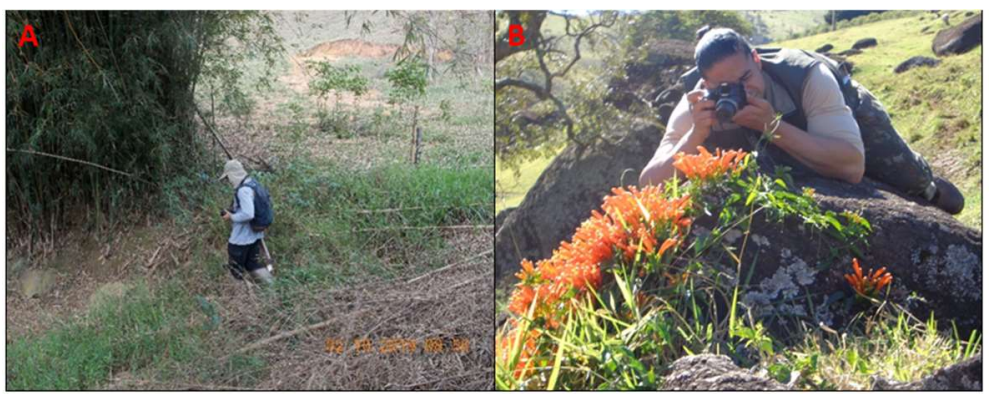

Figura 7: Levantamento de flora rupícola associada diretamente às cavidades.

\section{RESULTADOS E DISCUSSÃO}

\section{Espeleometria}

A cavidade aqui apresentada não se encontrada cadastrada no CANIE e consequentemente não possui nome oficial, portanto, foi denominada 'Cavidade do Morro Redondo', por estar localizada na região denominada Córrego do Morro Redondo. A cavidade do Morro Redondo localiza-se a cerca de $150 \mathrm{~m}$ do leito do Rio Pardo, em meio a vertente e a jusante do Rio. No local observa-se um abrigo rochoso, composto por granulito de pouco a medianamente alterados (Figura 8).

Ocorrem muitos desprendimentos de placas das paredes do afloramento rochoso próximo devido ao intemperismo, consequentemente há uma acumulação de blocos sobrepostos, os quais deram origem a cavidade, posteriormente esculpido por ação fluvial. Num reconhecimento preliminar, estimou-se uma altura do paredão em torno de 6 ou 7m. A projeção horizontal da cavidade é de 2,25 m, e a declividade é de 0,2 m. A altura da entrada da cavidade é de 1,88 m, com largura de 1,24m. 0 azimute medido a partir da base da entrada é de 2100 (Figura 9). Conforme Instrução Normativa no2 de 30 de agosto de 2017, por apresentar projeção horizontal inferior a cinco metros, a Cavidade do Morro Redondo não pode ser considerada para fins dos demais cálculos espeleométricos (área e volume). 
O piso é constituído por sedimentos argilosos e siltosos autogênicos, gerados a partir de material da própria rocha encaixante e material alogênico, provindo de ora da caverna. Há presença de blocos rochosos irregulares (Figura 9). Não foram identificados valores paleontológicos, históricos, cultural e socioeconômico na cavidade. Seu acesso pode ser feito através de trilha. $O$ entorno da cavidade apresenta vegetação árborea arbustiva.

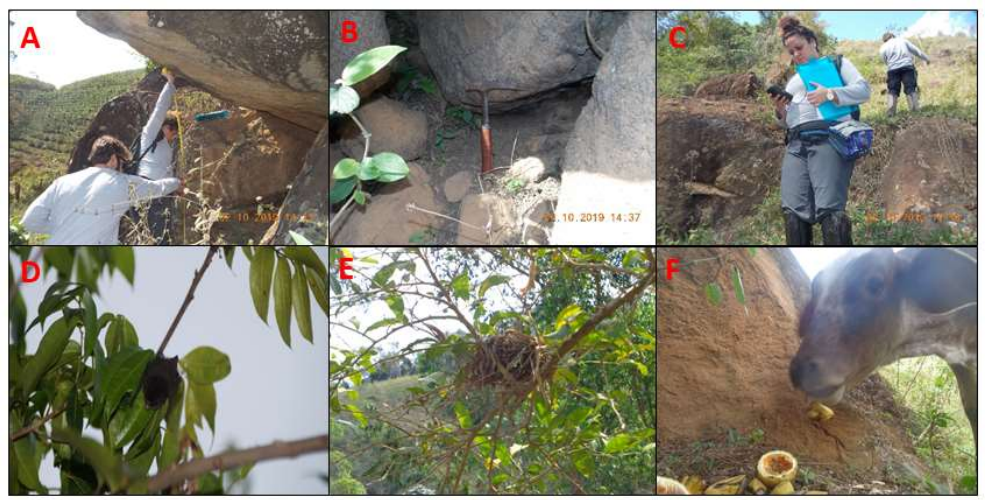

Figura 8: Fotografias da cavidade DO Morro Redondo. (A e B) Mensuração e interior da cavidade, respectivamente. (C) Entorno da cavidade. (D) Carollia perspicillata fotografado em vegetação na borda da cavidade. (E) ninho encontrado na borda da cavidade. (F) Bos tauros fotografado por câmera trap no interior da cavidade.

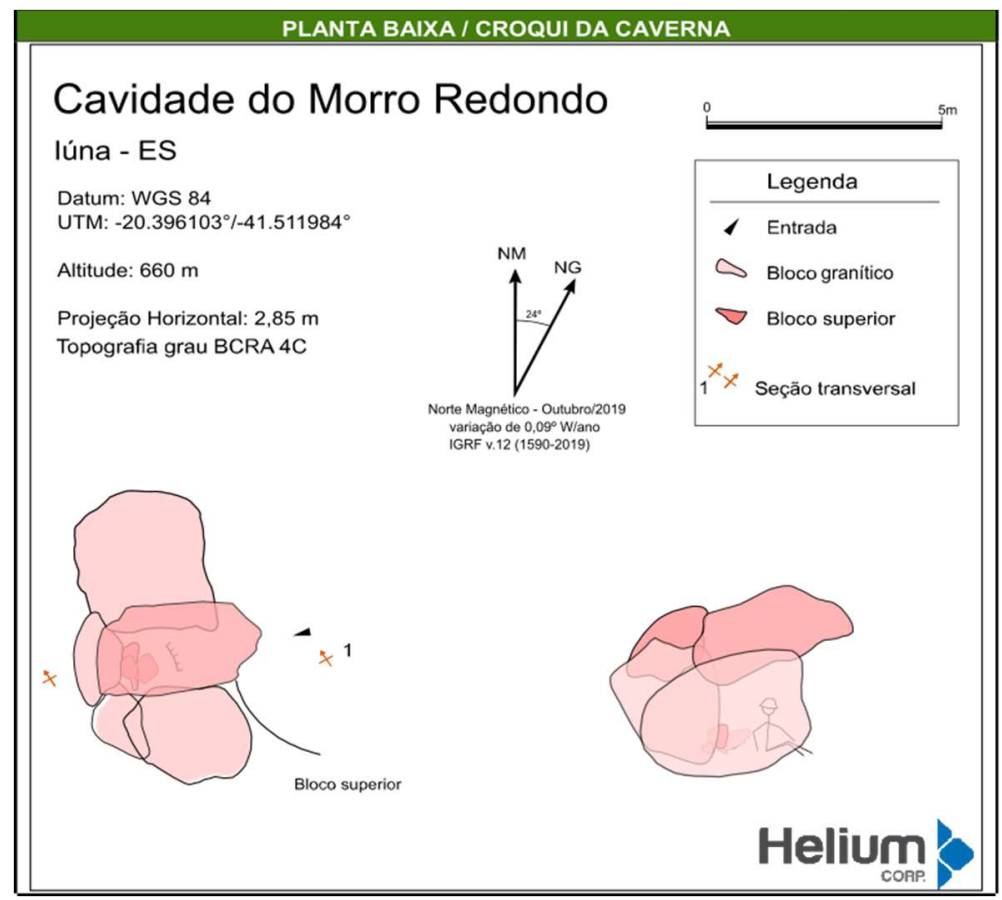

Figura 9: Planta baixa da Cavidade Morro Redondo.

\section{Biodiversidade Associada às Cavidades}

\section{Entomofauna Associada às Cavidades}

Durante a amostragem foram levantadas 48 espécies de Insetos, distribuídos em 10 ordens (Tabela 1), donde as espécies de Hymenoptera Tetragonisca angustula, Apis mellifera e Trigona spinipes são protegidas pela Resolução CONAMA n $346 / 2004$, que assegura e protege as abelhas nativas e adaptadas aos nossos sistemas ecológicos. Também foram levantados outros táxons de Insecta colonizando as cavidades que são Polistes versicolor, Pepsis sp., Polistes cf. canadenses, Polybia sp. e Myrmeleon sp., nenhum destes táxons possuem coevolução com ambientes cavernícolas, no entanto possuem grande afinidade com as 
bordas destes ambientes afóticos.

Tabela 1: Assembleia de insetos levantada na cavidade do Morro Redondo.

\begin{tabular}{|c|c|c|c|}
\hline Ordem & Família/Subfamília & Espécie & Nome vulgar \\
\hline Orthoptera & Melanoplinae & Ronderosia sp. & gafanhoto \\
\hline Orthoptera & Acrididae & Schistocerca sp. & gafanhoto \\
\hline Orthoptera & Tettigoniidae & Neoconocephalus sp. & esperança \\
\hline Orthoptera & Tettigoniidae & Xenicola sp. & esperança \\
\hline Hymenoptera & Polistinae & Polistes sp. & marimbondo \\
\hline Hymenoptera & Scoliidae & Scoliidae sp. & vespa \\
\hline Hymenoptera & Vespidae & Polistes lanio (FABRICIUS, 1775) & marimbondo \\
\hline Hymenoptera & Vespidae & Polybia sp. & marimbondo \\
\hline Hymenoptera & Apidae & Apis mellifera $\mathrm{L}$. & abelha \\
\hline Hymenoptera & Apidae & Trigona spinipes (Fabr.) & arapuã \\
\hline Hymenoptera & Apidae & Tetragonisca angustula (LATREILLE, 1811) & jataí \\
\hline Hymenoptera & Formicidae & Atta sexdens rubropilosa (FOREL, 1908) & saúva-limão \\
\hline Hymenoptera & Formicidae & Atta laevigata (SMITH 1858) & cabeça-de-vidro \\
\hline Hymenoptera & Formicidae & Acromyrmex sp. & quem-quem \\
\hline Hymenoptera & Camponotini & Camponotus sericeiventris (GUÉRIN, 1838) & formiga-onça \\
\hline Coleoptera & Cicindelinae & Megacephala sp. & cicindela \\
\hline Coleoptera & Chrysomelidae & Lema apicalis (LACORDAIRE, 1845) & besouro-praga \\
\hline Coleoptera & Coccinellidae & Cycloneda sanguínea L. & joaninha \\
\hline Coleoptera & Coccinellidae & Harmonia axyridis (PALLAS, 1773) & joaninha-asiática \\
\hline Coleoptera & Dynastinae & Coelosis bicornis (LESKE, 1779) & besouro-rinoceronte \\
\hline Coleoptera & Dynastinae & Cyclocephala sp. & besouro-amarelo \\
\hline Hemiptera heteroptera & Pentatomidae & Arvelius albopunctatus (DEGEER, 1773) & maria-fedida \\
\hline Hemiptera heteroptera & Pentatomidae & Edessa sp. & maria-fedida \\
\hline Hemiptera heteroptera & Pentatomidae & Peromatus sp. & maria-fedida \\
\hline Hemiptera Auchenorryncha & Membracidae & Membracis foliatafasciata (DEGEER, 1773) & soldadinho \\
\hline Hemiptera Auchenorryncha & Cercopidae & Maxantonia rubescens (LALLEMAND, 1949) & cigarrinha \\
\hline Lepdoptera & Pieridae & Urbanus sp. & borboleta \\
\hline Lepdoptera & Oiketicinae & Oiketicus sp. & borboleta \\
\hline Lepdoptera & Pieridae & Eurema sp. & borboleta \\
\hline Lepdoptera & Nymphalidae & Junonia evarete (CRAMER, 1779) & olho-de-pavão \\
\hline Lepdoptera & Nymphalidae & Anartia jatrophae (LINNAEUS, 1763) & pavão-branco \\
\hline Lepdoptera & Nymphalidae & Anartia amathea (LINNAEUS, 1758) & anartia \\
\hline Lepdoptera & Nymphalidae & Danaus sp. & monarca \\
\hline Lepdoptera & Nymphalidae & Heliconius ethilla narcaea (GODART, 1819) & heliconius \\
\hline Lepdoptera & Riodinidae & Synargis calyce (FELDER et al., 1862) & borboleta-cálice \\
\hline Lepdoptera & Nymphalidae & Hamadryas arete (DOUBLEDAY, 1847) & estaladeira \\
\hline Lepdoptera & Pieridae & Ascia monuste orseis (LATREILLE, 1819) & curuquerê-da-couve \\
\hline Lepdoptera & Erebidae & Ascalapha odorata (LINNAEUS, 1758) & bruxa \\
\hline Isoptera & Rhinotermitidae & Rhinotermes. Sp. & cupim \\
\hline Isoptera & Termitidae & Nasutitermes sp. & cupim \\
\hline Diptera & Culicidae & Aedes albopictus (SKUSE, 1894) & mosquito-tigre-asiático \\
\hline Diptera & Culicidae & Culex sp. & mosquito \\
\hline Diptera & Asilidae & Asilidae sp. & mosca-predadora \\
\hline Diptera & Tabanidae & Tabanus sp. & mutuca \\
\hline Odonata & Lestidae & Lestes sp. & donzelinha \\
\hline Odonata & Libellulidae & Orthemis ferruginea (FABRICIUS, 1775) & libélula \\
\hline Neuroptera & Myrmeleontidae & Myrmeleon sp. & formiga-leão \\
\hline Neuroptera & Chrysopidae & Chrysopidae sp. & bicho-lixeiro \\
\hline
\end{tabular}

As ordens de Insecta com maior destaque para área de influência direta (AID) do entorno da cavidade foram Hymenoptera e Lepdoptera, dentre os mutualistas-chave que são as espécies envolvidas numa relação de mutualismo (interações mutuamente benéficas, como o caso da polinização de plantas por insetos) têmse estas ordens como as principais prestadoras do serviço de polinização no globo terrestre, justificando assim a sua proteção pelo Conselho Nacional do Ambiente (CONAMA). Para a autoecologia destas espécies de apídeos é normal seu levantamento na porta de entrada de cavidades naturais subterrâneas (KERR et al., 2001). No entanto, é importante ressaltar que apídeos não estão entre os táxons troglóbios de ambientes 
cavernícolas, mas sim troglófilos, isto é, que possuem afinidade com estes ecossistemas, mas que não necessitam do mesmo para sobreviver e completar sua história de vida.

\section{Araneofauna Associada às Cavidades}

Durante a amostragem foram levantadas 9 espécies de aranhas para a araneofauna (Tabela 2). Nenhuma espécie se encontra ameaçada nacionalmente ou internacionalmente. Não foram registrados chelicerados com estruturas troglomórficas ou que sejam trogloxenos. Nem espécies consideradas de importância médica.

Tabela 2: Assembleia de aranhas levantadas na cavidade do Morro Redondo.

\begin{tabular}{|l|l|l|l|}
\hline Ordem & Família/Subfamília & Espécie & Nome vulgar \\
\hline Aranae & Nephilidae & Nephilengys cruentata chiloangensis (STRAND, 1919) & aranha-de-telhado \\
\hline Aranae & Lycosidae & Lycosa erythrognatha. (LUCAS, 1836) & aranha-da-grama \\
\hline Aranae & Argiopinae & Argiope argentata (FABRICIUS, 1775) & aranha-de-prata \\
\hline Aranae & Dipluridae & Trechona sp. & caranguejeira \\
\hline Aranae & Trechaleidae & Trechalea sp. & aranha-do-líquen \\
\hline Aranae & Sparassidae & Olios sp. & aranha-verde \\
\hline Aranae & Salticidae & Maeota sp. & papa-moscas \\
\hline Aranae & Salticidae & Maeota dichrura (SIMON, 1901) & papa-moscas \\
\hline Aranae & Theraphosidae & Lasiodora sp. & caranguejeira \\
\hline
\end{tabular}

\section{Herpetofauna Associada às Cavidades}

O método de coleta por busca ativa foi responsável pela interceptação de seis espécies táxons para a herpetofana, dos quais 3 são répteis e 3 são anfíbios, dos quais a espécie Salvator merianae, possui categoria de ameaça II para a lista CITES (Convention on International Trade in Endangered Species of Wild Fauna and Flora), isto é, embora atualmente não se encontre necessariamente em perigo de extinção, poderá chegar a esta situação a menos que o comércio de espécimes de tais espécies esteja sujeito a regulamentação rigorosa (Tabela 3).

As demais espécies levantadas possuem larga distribuição, sendo facilmente encontradas em áreas de pasto com intensa antropização e fragmentação florestal e não necessitam de cavidades naturais subterrâneas para completar a sua história de vida, no entanto quando existentes, utilizam as cavidades para abrigo, obtenção de alimentos e refúgio da vida silvestre.

Tabela 3: Herpetofauna levantada na cavidade do Morro Redondo.

\begin{tabular}{|l|l|l|l|}
\hline Ordem & Família/Subfamília & Espécie & Nome vulgar \\
\hline Anura & Bufonidae & Rhinella schneideri (WERNER, 1894) & Sapo-boi \\
\hline Anura & Bufonidae & Rhinella ornata (SPIX, 1824) & sapo-cururuzinho \\
\hline Anura & Leptodactylidae & Leptodactylus fuscus (SCHNEIDER, 1799) & rã-assobiadeira \\
\hline Squamata & Teiidae & Salvator merianae (DUMÉRIL et al., 1839) & teiú \\
\hline Squamata & Tropiduridae & Tropidurus torquatus (WIED, 1820) & calango \\
\hline Squamata & Gekkonidae & Hemidactylus mabouia (JONNES, 1818) & lagartixa-doméstica-tropical \\
\hline
\end{tabular}

\section{Avifauna Associada às Cavidades}

Para a cavidade do morro redondo, foi constatado da avifauna da tabela 4 utilizando a cavidade do Morro Redondo para completar a sua história de vida. 
Tabela 4: Espécies da avifauna registradas para a cavidade do Morro Redondo.

\begin{tabular}{|c|c|c|c|c|c|c|c|c|c|c|}
\hline Táxon & Nome Popular & Guilda Tróf & SS & RG & HB & MI & ED & IV & CN & $\mathrm{Xe}$ \\
\hline \multicolumn{11}{|c|}{ Passeriformes (Linnaeus, 1758) } \\
\hline \multicolumn{11}{|c|}{ Hirundinidae (Rafinesque, 1815) } \\
\hline $\begin{array}{l}\text { Progne tapera } \\
\text { (Vieillot, 1817) }\end{array}$ & $\begin{array}{l}\text { Andorinha-do- } \\
\text { campo }\end{array}$ & Insetívoro & Baixa & Visua/ Áudio & ind & Mig & & & & \\
\hline $\begin{array}{l}\text { Progne chalybea } \\
\text { (Gmelin, 1789) }\end{array}$ & $\begin{array}{c}\text { Andorinha- } \\
\text { doméstica-grande }\end{array}$ & Insetívoro & Baixa & Visua/ Áudio & ind & Mig & & & & \\
\hline $\begin{array}{c}\text { Pygochelidon } \\
\text { cyanoleuca (Vieillot, } \\
1817 \text { ) }\end{array}$ & $\begin{array}{l}\text { Andorinha- } \\
\text { doméstica- } \\
\text { pequena }\end{array}$ & Insetívoro & Baixa & Visua/ Áudio & ind & Mig & & & & \\
\hline \multicolumn{11}{|c|}{ Troglodytidae (Swainson, 1831) } \\
\hline $\begin{array}{l}\text { Troglodytes musculus } \\
\text { (Naumann, 1823) }\end{array}$ & Corruíra & Insetívoro & Baixa & Visua/ Áudio & ind & & & & & \\
\hline \multicolumn{11}{|c|}{ Thamnophilidae (Swainson, 1824) } \\
\hline $\begin{array}{c}\text { Thamnophilus } \\
\text { palliatus } \\
\text { (Lichtenstein, 1823) }\end{array}$ & Choca-listrada & Insetívoro & Baixa & Visua/ Áudio & ind & & & & & \\
\hline \multicolumn{11}{|c|}{ Furnariidae (Grey, 1840) } \\
\hline $\begin{array}{l}\text { Furnarius rufus } \\
\text { (Gmelin, 1788) } \\
\end{array}$ & João-de-barro & Insetívoro & Baixa & Visua/ Áudio & ind & & & & & \\
\hline $\begin{array}{c}\text { Phacellodomus } \\
\text { rufifrons (Wied, 1821) }\end{array}$ & João-de-pau & Insetívoro & Baixa & Visua/ Áudio & ind & & & & & \\
\hline \multicolumn{11}{|c|}{ Falconiformes (Leach, 1820) } \\
\hline \multicolumn{11}{|c|}{ Falconidae (Leach, 1820) } \\
\hline $\begin{array}{l}\text { Caracara plancus } \\
\text { (Miller, 1777) }\end{array}$ & Carácará & Carnívoro & Baixa & Visua/ Áudio & ind & & & & & $\mathrm{Xe}$ \\
\hline
\end{tabular}

Legenda: Xerimbabo (Xe), cinegéticas (CN), endêmicas (ED), invasoras (IV), habitat preferencial (HB)- ind: independente de ecossistema florestal; dep: dependente de ecossistema florestal; sem: semidependente de ecossistema florestal, sensitividade a distúrbios ambientais (SS), registro (RG), migrantes (MI) e Guilda trófica (Guilda Tróf.).

Destas espécies, Caracara plancus possui categoria de ameaça II para a lista CITES, e as espécies Pygochelidon cyanoleuca, Progne tapera e Progne chalybea são migratórias. Ressalta-se que a borda da cavidade apresentou nidificação para a espécie Thamnophilus palliatus (Figura 8).

\section{Mastofauna Associada às Cavidades}

Durante as atividades de campo, não foram registrados mamíferos silvestres terrestres no interior das cavidades, a única espécie de mamífero registrada no interior da cavidade foi da espécie Bos tauros (Figura 8). Não significando que mamíferos silvestres não usem a cavidade do Morro Redondo em sua história de vida, no entanto a pressão antrópica do entorno é altíssima, podendo influenciar diretamente na presença ou ausência de mamíferos silvestres (SILVA et al., 2017), que são mais abundantes e frequentes em ambientes, cuja sinergia e homeostase não foram desequilibradas pelas ações do homem. Para mamíferos voadores, realizou-se o registro da espécie Carollia perspicillata, na borda da cavidade, todavia não é uma espécie dependente dos ambientes cavernícolas para completar a sua história de vida (VIEIRA et al., 2017).

\section{Flora Associada às Cavidades}

Foram registradas 46 espécies vegetais em associação direta com a cavidade do morro redondo, donde nenhuma possui status de ameaça para a portaria MMA no 443/2014. Grande parte das espécies levantadas possui íntima relação com a quiropetrofauna como as espécies botânicas (MELLO, 2002; MULLER 
et al., 1992): Anthurium coriaceum, Piper arboreum, e Piper mollicomum. As espécies de morcegos da família Phyllostomidae, registrados para este estudo, são dispersoras destas espécies, que são características de ambientes com formação florestal capoeira e Floresta ombrófila em estágio inicial.

Tabela 5: Lista de espécies amostradas no levantamento florístico classificadas por: família, hábito, origem e grau de ameaça.

\begin{tabular}{|c|c|c|c|c|c|c|c|c|}
\hline Família Botânica & Táxon & Vern & Origem & Sínd & Suc & Sub & Forma de Vida & St \\
\hline Araceae & $\begin{array}{c}\text { Anthurium } \\
\text { coriaceum } \\
\text { (Graham) } \\
\text { G.Don }\end{array}$ & - & Nativa & Zoo & $\mathrm{Pi}$ & Rupícola & Erva & $\mathrm{LC} / \mathrm{LC}$ \\
\hline Asteraceae & $\begin{array}{l}\text { Vernonanthura } \\
\text { polyanthes } \\
\text { (Sprengel) Vega } \\
\text { \& Dematteis }\end{array}$ & $\begin{array}{l}\text { assa- } \\
\text { peixe }\end{array}$ & Nativa & Ane & $\mathrm{Pi}$ & Terrícola & Arbusto & $\mathrm{NE} / \mathrm{NE}$ \\
\hline Asteraceae & $\begin{array}{c}\text { Baccharis } \\
\text { trimera (Less.) }\end{array}$ & Carquejo & $\begin{array}{c}\text { Nativa/ } \\
\text { Cosmopolita }\end{array}$ & Ane & $\mathrm{Pi}$ & Terrícola & Erva & $\mathrm{NE} / \mathrm{NE}$ \\
\hline Asteraceae & $\begin{array}{c}\text { Bidens alba (L.) } \\
\text { DC. }\end{array}$ & Picão & $\begin{array}{c}\text { Nativa/ } \\
\text { Cosmopolita }\end{array}$ & Zoo & $\mathrm{Pi}$ & Terrícola & Erva & $\mathrm{NE} / \mathrm{NE}$ \\
\hline Asteraceae & $\begin{array}{c}\text { Chaptalia } \\
\text { integerrima } \\
\text { (Vell.) Burkart }\end{array}$ & $\begin{array}{l}\text { língua- } \\
\text { de-vaca }\end{array}$ & Nativa & Ane & $\mathrm{Pi}$ & Terrícola & Erva & $\mathrm{NE} / \mathrm{NE}$ \\
\hline Asteraceae & $\begin{array}{c}\text { Eclipta } \\
\text { prostrata (L.) }\end{array}$ & $\begin{array}{c}\text { agrião- } \\
\text { do-brejo }\end{array}$ & $\begin{array}{c}\text { Nativa/ } \\
\text { Cosmopolita }\end{array}$ & Ane & $\mathrm{Pi}$ & Terrícola & Erva & $\mathrm{LC} / \mathrm{NE}$ \\
\hline Asteraceae & $\begin{array}{l}\text { Gamochaeta } \\
\text { coarctata } \\
\text { (Willd.) } \\
\text { Kerguélen }\end{array}$ & $\begin{array}{l}\text { erva- } \\
\text { macia }\end{array}$ & Nativa & Aut & $\mathrm{Pi}$ & Terrícola & Erva & $\mathrm{NE} / \mathrm{NE}$ \\
\hline Asteraceae & $\begin{array}{c}\text { Mikania } \\
\text { cordifolia (L. f.) } \\
\text { Willd. }\end{array}$ & $\begin{array}{l}\text { cipó- } \\
\text { cabeludo }\end{array}$ & Nativa & Ane & $\mathrm{Pi}$ & Terrícola & Erva & $\mathrm{NE} / \mathrm{NE}$ \\
\hline Asteraceae & $\begin{array}{l}\text { Pterocaulon } \\
\text { virgatum (L.) } \\
\text { DC. }\end{array}$ & $\begin{array}{l}\text { alecrim- } \\
\text { das- } \\
\text { paredes }\end{array}$ & Nativa & Ane & Sc & Terrícola & Erva & $\mathrm{NE} / \mathrm{NE}$ \\
\hline Asteraceae & $\begin{array}{c}\text { Sphagneticola } \\
\text { trilobata (L.) } \\
\text { Pruski }\end{array}$ & $\begin{array}{l}\text { mal-me- } \\
\text { quer }\end{array}$ & $\begin{array}{c}\text { Nativa/ } \\
\text { Cosmopolita }\end{array}$ & Aut & $\mathrm{Pi}$ & Terrícola & $\begin{array}{l}\text { Erva|trepadeira } \\
\text { terrestre }\end{array}$ & $\mathrm{NE} / \mathrm{NE}$ \\
\hline Asteraceae & $\begin{array}{c}\text { Tridax } \\
\text { procumbens L. }\end{array}$ & $\begin{array}{l}\text { erva-de- } \\
\text { touro }\end{array}$ & $\begin{array}{c}\text { Nativa/ } \\
\text { Cosmopolita }\end{array}$ & Ane & $\mathrm{Pi}$ & Terrícola & Erva & $\mathrm{NE} / \mathrm{NE}$ \\
\hline Bignoniaceae & $\begin{array}{l}\text { Amphilophium } \\
\text { crucigerum (L.) } \\
\text { L.G.Lohmann }\end{array}$ & $\begin{array}{l}\text { escova- } \\
\text { de-cavalo }\end{array}$ & Nativa & Ane & $\mathrm{Pi}$ & Terrícola & $\begin{array}{l}\text { Liana|volúvel| } \\
\text { trepadeira }\end{array}$ & $\mathrm{NE} / \mathrm{NE}$ \\
\hline Bignoniaceae & $\begin{array}{c}\text { Pyrostegia } \\
\text { venusta (Ker } \\
\text { Gawl.) }\end{array}$ & $\begin{array}{l}\text { flor-de- } \\
\text { são-joão }\end{array}$ & Nativa & Ane & $\mathrm{Pi}$ & $\begin{array}{c}\text { Epífita|Rupícola| } \\
\text { Terrícola }\end{array}$ & $\begin{array}{l}\text { Liana|volúvel| } \\
\text { trepadeira }\end{array}$ & $\mathrm{NE} / \mathrm{NE}$ \\
\hline Bromeliaceae & $\begin{array}{c}\text { Aechmea } \\
\text { bromeliifolia } \\
\text { (Rudge) Baker }\end{array}$ & - & Nativa & Ane & $\mathrm{Pi}$ & $\begin{array}{c}\text { Epífita|Rupícola| } \\
\text { Terrícola }\end{array}$ & Erva & $\mathrm{NE} / \mathrm{NE}$ \\
\hline Bromeliaceae & Aechmea sp.1 & - & $\mathrm{NA}$ & Ane & $\mathrm{Si}$ & Epífita & Erva & - \\
\hline Bromeliaceae & $\begin{array}{c}\text { Hohenbergia } \\
\text { sp.1 }\end{array}$ & - & NA & Ane & $\mathrm{Si}$ & Terrícola & Erva & - \\
\hline Bromeliaceae & $\begin{array}{c}\text { Pitcairnia } \\
\text { flammea Lindl. }\end{array}$ & - & Nativa & Ane & $\mathrm{Si}$ & $\begin{array}{c}\text { Rupícola| } \\
\text { Terrícola }\end{array}$ & Erva & $\mathrm{NE} / \mathrm{NE}$ \\
\hline Bromeliaceae & $\begin{array}{c}\text { Tillandsia } \\
\text { stricta Solander }\end{array}$ & Tillandsia & Nativa & Zoo & $\mathrm{Si}$ & epífita/rupícola & Erva & $\mathrm{NE} / \mathrm{NE}$ \\
\hline Bromeliaceae & $\begin{array}{c}\text { Tillandsia } \\
\text { gardneri Lindl. }\end{array}$ & Tillandsia & Nativa & Zoo & $\mathrm{Si}$ & epífita/rupícola & Erva & $\mathrm{NE} / \mathrm{NE}$ \\
\hline Cactaceae & $\begin{array}{c}\text { Hylocereus } \\
\text { undatus (Haw.) } \\
\text { Britton \& Rose }\end{array}$ & pitaya & naturalizada & Zoo & $\mathrm{Pi}$ & $\begin{array}{c}\text { Epífita| } \\
\text { Hemiepífita| } \\
\text { Rupícola| Terrícola }\end{array}$ & $\begin{array}{l}\text { Liana|volúvel|trepad } \\
\text { eira| Suculenta }\end{array}$ & $\mathrm{DD} / \mathrm{NE}$ \\
\hline Cleomaceae & $\begin{array}{c}\text { Tarenaya rosea } \\
\text { (Vahl ex DC.) } \\
\text { Soares Neto \& } \\
\text { Roalson }\end{array}$ & - & Nativa & Ane & $\mathrm{Pi}$ & Terrícola & Erva & $\mathrm{NE} / \mathrm{NE}$ \\
\hline Commelinaceae & $\begin{array}{c}\text { Commelina } \\
\text { erecta } \mathrm{L} .\end{array}$ & - & Nativa & Aut & $\mathrm{Pi}$ & $\begin{array}{c}\text { Rupícola| } \\
\text { Terrícola } \\
\end{array}$ & Erva & $\mathrm{LC} / \mathrm{NE}$ \\
\hline Commelinaceae & $\begin{array}{c}\text { Dichorisandra } \\
\text { thyrsiflora J.C. } \\
\text { Mikan. }\end{array}$ & - & Nativa & Aut & $\mathrm{Si}$ & Terrícola & Erva & $\mathrm{NE} / \mathrm{NE}$ \\
\hline Cucurbitaceae & $\begin{array}{l}\text { Momordica } \\
\text { charantia } \mathrm{L}\end{array}$ & $\begin{array}{l}\text { melão- } \\
\text { de-são- }\end{array}$ & Nativa & Zoo & $\mathrm{Pi}$ & $\begin{array}{c}\text { Epífita|Rupícola| } \\
\text { Terrícola }\end{array}$ & $\begin{array}{c}\text { Liana|volúvel| } \\
\text { trepadeira }\end{array}$ & $\mathrm{NE} / \mathrm{NE}$ \\
\hline
\end{tabular}




\begin{tabular}{|c|c|c|c|c|c|c|c|c|}
\hline & & caetano & & & & & & \\
\hline Dilleniaceae & $\begin{array}{l}\text { Davilla rugosa } \\
\text { Poir. }\end{array}$ & cipó-fogo & Nativa & Zoo & $\mathrm{Pi}$ & Terrícola & $\begin{array}{c}\text { Liana|volúvel| } \\
\text { trepadeira| } \\
\text { Subarbusto }\end{array}$ & $\mathrm{NE} / \mathrm{NE}$ \\
\hline Euphorbiaceae & $\begin{array}{l}\text { Dalechampia } \\
\text { scandens L. }\end{array}$ & - & Nativa & Aut & $\mathrm{Pi}$ & Terrícola & $\begin{array}{c}\text { Liana|volúvel| } \\
\text { trepadeira }\end{array}$ & $\mathrm{NE} / \mathrm{NE}$ \\
\hline Myrtaceae & $\begin{array}{c}\text { Psidium } \\
\text { guajava } \mathrm{L} .\end{array}$ & goiabeira & cultivada & Zoo & $\mathrm{Pi}$ & Terrícola & Árvore|arbusto & $\mathrm{LC} / \mathrm{NE}$ \\
\hline Myrtaceae & $\begin{array}{c}\text { Psidium } \\
\text { guineense Sw. }\end{array}$ & $\begin{array}{c}\text { goiaba- } \\
\text { araçá }\end{array}$ & Nativa & Zoo & $\mathrm{Pi}$ & Terrícola & Árvore & $\mathrm{LC} / \mathrm{NE}$ \\
\hline Passifloraceae & Passiflora sp.1 & $\begin{array}{l}\text { maracujá } \\
\text {-do-mato }\end{array}$ & NA & Zoo & Sc & Terrícola & Trepadeira & - \\
\hline Phytolaccaceae & $\begin{array}{c}\text { Seguieria } \\
\text { langsdorffii } \\
\text { Moq. }\end{array}$ & agulheiro & Nativa & Ane & $\mathrm{Pi}$ & Terrícola & Árvore & NE/LC \\
\hline Piperaceae & $\begin{array}{c}\text { Piper arboreum } \\
\text { Aubl. }\end{array}$ & $\begin{array}{l}\text { batom- } \\
\text { de- } \\
\text { mulata }\end{array}$ & Nativa & Zoo & $\mathrm{Pi}$ & Terrícola & Arbusto & $\mathrm{NE} / \mathrm{NE}$ \\
\hline Piperaceae & $\begin{array}{l}\text { Piper } \\
\text { mollicomum } \\
\text { Kunth }\end{array}$ & $\begin{array}{l}\text { aperta- } \\
\text { ruão }\end{array}$ & Nativa & Zoo & $\mathrm{Pi}$ & Terrícola & Arbusto & $\mathrm{NE} / \mathrm{NE}$ \\
\hline Plantaginaceae & $\begin{array}{c}\text { Plantago } \\
\text { tomentosa Lam. }\end{array}$ & $\begin{array}{l}\text { língua- } \\
\text { de-vaca }\end{array}$ & $\begin{array}{c}\text { Nativa/ } \\
\text { Cosmopolita }\end{array}$ & Aut & $\mathrm{Pi}$ & Terrícola & Arbusto & $\mathrm{NE} / \mathrm{NE}$ \\
\hline Poaceae & $\begin{array}{c}\text { Bambusa } \\
\text { vulgaris Schrad. } \\
\text { ex J.C.Wendl. }\end{array}$ & bambu & exótica & Ane & Sc & Terrícola & Árvore & $\mathrm{NE} / \mathrm{NE}$ \\
\hline Poaceae & $\begin{array}{c}\text { Megathyrsus } \\
\text { maximus (Jacq.) } \\
\text { B.K.Simon \& } \\
\text { S.W.L.Jacobs }\end{array}$ & $\begin{array}{l}\text { capim- } \\
\text { colonião }\end{array}$ & exótica & Ane & Sc & Terrícola & Arbusto|Erva & $\mathrm{NE} / \mathrm{NE}$ \\
\hline Poaceae & Urochloa sp.1 & $\begin{array}{c}\text { braquiári } \\
\text { a }\end{array}$ & NA & Aut & Sc & Terrícola & Erva & - \\
\hline Poaceae & $\begin{array}{c}\text { Andropogon } \\
\text { bicornis L. }\end{array}$ & $\begin{array}{l}\text { capim- } \\
\text { rabo-de- } \\
\text { burro }\end{array}$ & Nativa & Zoo & $\mathrm{Pi}$ & Terrícola & Erva & $\mathrm{NE} / \mathrm{NE}$ \\
\hline Poaceae & Briza minor L. & $\begin{array}{l}\text { capim- } \\
\text { treme- } \\
\text { treme }\end{array}$ & exótica & Aut & Sc & Terrícola & Erva & $\mathrm{NE} / \mathrm{NE}$ \\
\hline Poaceae & $\begin{array}{c}\text { Digitaria ciliaris } \\
\text { (Retz.) Koeler }\end{array}$ & $\begin{array}{l}\text { capim- } \\
\text { colchão }\end{array}$ & exótica & Aut & Sc & Terrícola & Erva & $\mathrm{NE} / \mathrm{NE}$ \\
\hline Poaceae & $\begin{array}{c}\text { Melinis } \\
\text { minutiflora P. } \\
\text { Beauv. }\end{array}$ & $\begin{array}{l}\text { campim- } \\
\text { gordura }\end{array}$ & exótica & Ane & Sc & Terrícola & Erva & $\mathrm{NE} / \mathrm{NE}$ \\
\hline Poaceae & $\begin{array}{c}\text { Paspalum } \\
\text { notatum Flüggé }\end{array}$ & $\begin{array}{l}\text { Capim- } \\
\text { batatais }\end{array}$ & exótica & Ane & Sc & Terrícola & Erva & $\mathrm{NE} / \mathrm{NE}$ \\
\hline Portulacaceae & Portulaca sp.1 & $\begin{array}{l}\text { berldroe } \\
\text { ga-de- } \\
\text { gnomo }\end{array}$ & NA & Aut & Sc & $\begin{array}{c}\text { Terrícola|epífita| } \\
\text { rupícola }\end{array}$ & Erva & - \\
\hline Rhamnaceae & $\begin{array}{c}\text { Gouania } \\
\text { blanchetiana } \\
\text { Miq. }\end{array}$ & $\begin{array}{l}\text { sabão- } \\
\text { de-moça }\end{array}$ & $\begin{array}{c}\text { Nativa/ } \\
\text { Cosmopolita }\end{array}$ & Ane & $\mathrm{Pi}$ & Terrícola & $\begin{array}{l}\text { Liana|volúvel| } \\
\text { trepadeira }\end{array}$ & $\mathrm{NE} / \mathrm{NE}$ \\
\hline Rubiaceae & $\begin{array}{c}\text { Coffea arabica } \\
\text { L. }\end{array}$ & Café & cultivada & Zoo & Sc & Terrícola & Arbusto & EN/NE \\
\hline Solanaceae & $\begin{array}{c}\text { Solanum } \\
\text { cordifolium } \\
\text { Dunal }\end{array}$ & - & Nativa & Zoo & $\mathrm{Pi}$ & Terrícola & $\begin{array}{c}\text { Arbusto|Liana| } \\
\text { volúvel/trepadeira }\end{array}$ & $\mathrm{NE} / \mathrm{NE}$ \\
\hline Thelypteridaceae & $\begin{array}{c}\text { Thelypteris } \\
\text { dentata } \\
\text { (Forssk.) E. P. } \\
\text { St. John }\end{array}$ & - & $\begin{array}{c}\text { Nativa/ } \\
\text { Cosmopolita }\end{array}$ & Hidr & Sc & Terrícola & Erva & $\mathrm{NE} / \mathrm{NE}$ \\
\hline
\end{tabular}

Legenda: Vern: vernáculo; St.-Status: IUCN (The International Union for Conservation of Nature); CNC (Centro Nacional de Conservação da Flora - Livro Vermelho da Flora do Brasil), Categoria de ameaça: $L C=$ Pouco preocupante, NE= Sem informação, $D D=$ Dados insuficientes, EN= Ameaçada de extinção. Sub: Substrato; Suc.: Sucessão= Pi (pioneira), Si- Secundária inicial, Sc- Sem classificação. Sínd: Síndrome dispersiva= Zoocórica (Zoo), Hidrocórica (Hidr), Autocórica (Aut), Anemocórica (Ane).

Das 46 espécies registradas, 15 espécies são dispersadas por animais, possuindo assim relação coevolutiva com a fauna silvestre, logo a maior parte das espécies registradas, não possui relação com a fauna silvestre, indicando que o entorno da cavidade se encontra extremamente descaracterizado e com pouca conectividade com os ambientes florestais. 


\section{Relevância da Cavidade do Morro Redondo}

Segundo a instrução normativa no 02, de 30 de agosto de 2017, a cavidade natural subterrânea será classificada de acordo com seu grau de relevância em máximo, alto, médio ou baixo. De acordo com esta instrução normativa, as cavidades naturais subterrâneas com menos de cinco metros de desenvolvimento linear, serão classificadas com baixo grau de relevância, desde que demonstrada a inexistência de: zona afótica, destacada relevância histórico-cultural ou religiosa, presença de depósitos químicos, clásticos ou biogênicos de significativo valor científico, cênico ou ecológico; ou função hidrológica expressiva para o sistema cárstico.

Do ponto de vista histórico e cultural, não foi constado nenhum uso humano nas cavidades e o impacto humano direto na mesma se dá pela agricultura e pecuária do entorno que descaracteriza significativamente todo elemento cênico e natural do entorno da cavidade do morro redondo.

A cavidade do morro redondo não apresentou atributos bióticos, abióticos e culturais de grande relevância, isto é, sobre o enfoque local e regional. Não ocorreu registro de geoestruturas de relevância espeleotemática, ou representatividade faunística, cuja história de vida tenha relação direta com as cavidades, nem representantes rupícolas da flora que se encontrem em alguma lista nacional ou internacional de ameaça, dentro do interesse dos ecossistemas brasileiros, todavia caso sejam implantados empreendimentos na sub-bacia do rio Pardo, é recomendável a conservação do patrimônio espeleológico pela metodologia da valoração ambiental proposta por Almeida et al. (2013).

\section{CONCLUSÕES}

O inventário bioespeleológico da cavidade do Morro Redondo, possibilitou o registro da biocenose composta por 48 espécies de insetos, distribuídos em 10 ordens, para a ordem Hymenoptera, as espécies Tetragonisca angustula, Apis mellifera e Trigona spinipes são protegidas pela Resolução CONAMA $n^{\circ}$ 346/2004, que assegura e protege as abelhas nativas e adaptadas aos nossos sistemas ecológicos. Para araneofauna foram registradas 9 espécies de aranhas, distribuídas em 8 famílias. Não foram registrados chelicerados com estruturas troglomórficas ou que sejam trogloxenos. Para a herpetofauna 3 são répteis e 3 são anfíbios, onde Salvator merianae possui categoria II de ameaça na lista CITES, no entanto não é uma espécie que necessita de ambientes cavernícolas para completar sua história de vida. Para a avifauna foram registradas 8 espécies, distribuídas em 5 famílias e 2 ordens, a espécie Caracara plancus possui categoria II de ameaça no CITES, no entanto nenhuma das espécies da avifauna necessita de ambientes cavernícolas para completar sua história de vida, foi efetuado o registro de nidificação da espécie Thamnophilus palliatus na borda da cavidade do Morro Redondo. A única espécie de mamífero silvestre registrada para a cavidade foi o morcego Carollia perspicillata que não necessita de cavidades para completar a sua história de vida. Das 46 espécies botânicas levantadas, nenhuma se encontram ameaçada, todavia as espécies Anthurium coriaceum, Piper arboreum, e Piper mollicomum, são dispersadas por morcegos da família Phyllostomidae.

Não foram levantados registros paleontológicos ou de contexto histórico e cultural, sendo conclusivo 
que a cavidade do morro redondo possui baixa relevância segundo a instrução normativa $\mathrm{n}$ o 02 , de 30 de agosto de 2017. Espera-se que os resultados deste trabalho científico possam contribuir significativamente para a caracterização espeleológica do município de lúna e da Serra do Caparaó.

AGRADECIMENTOS: À Companhia Brasileira de Produção Científica (CBPC) pela releitura, organização e editoração desta obra. À Helium Corp. Engenharia, pelo financiamento e contribuição científica. À turma 2008/01 de engenharia florestal da UFRRJ.

\section{REFERÊNCIAS}

ANA. Agência Nacional de Águas. Evolução da organização e implementação da gestão de bacias no Brasil. Brasília: ANA, 2007.

ALMEIDA, J. R.; CASTRO, S. M.; RODRIGUES, M. G.. Valoração de dados ambientais da geração termelétrica: usina de Santa Cruz/RJ. Revista Internacional de Ciências, v.2, p.41-51, 2013. DOI: http://doi.org/10.12957/ric.2012.4938

BACKES, P.; IRGANG, B.. Árvores cultivadas no Sul do Brasil: Guia de identificação e interesse paisagístico das principais espécies exóticas. Paisagem do Sul, 2004.

BRANDI, R.. Grupo Bambuí de Pesquisas Espeleológicas. 0 Carste, 2012.

BRASIL. Ministério do Meio Ambiente. Conselho Nacional do Meio Ambiente. Resolução CONAMA n. 347, de 10 de setembro de 2004. Regulamentada pelo Decreto no 99.274, de 6 de julho de 1990, e tendo em disposto em seu Regimento Interno, aprovado pela Portaria no 499, de 18 de dezembro de 2002. Brasília: DOU, 2004.

BRASIL. Ministério do Meio Ambiente. Decreto n. 6.640, de 7 de novembro de 2008. Brasília: DOU, 2008.

BRASIL. Ministério do Meio Ambiente. Portaria MMA N. 443, DE 17 de dezembro de 2014. Brasília: DOU, 2014.

BRASIL. Ministério do Meio Ambiente. Instrução Normativa n. 2, de 30 de agosto de 2017. Brasília: DOU, 2017.

BRASIL. Decreto n.99.556, de 01 de outubro de 1990 Dispõe sobre a proteção das cavidades naturais subterrâneas existentes no Território Nacional e dá outras providências. Brasília: DOU, 1990.

CABRERA, A. L.; WILLINK, A.. Biogeografia de América Latina. Monografia. Washington: OEA, 1973.

CECAV. Centro de Pesquisa e Conservação de Cavernas. IV Curso de espeleologia e licenciamento ambiental. CECAV, 2013.

CECAV. Centro de Pesquisa e Conservação de Cavernas. Espeleologia e licenciamento ambiental. Brasília: ICMBIO, 2019.

DAY, A.. Cave Surveying [Cave Studies Series 11]. Buxton: British Cave Research Association, 2002.
ESPÍRITO SANTO. Secretaria de Estado da Agricultura, Abastecimento, Aquicultura e Pesca. Plano estratégico de desenvolvimento da agricultura capixaba-novo Pedeag 2007-2025: região do Caparaó. Caparaó, 2008.

ICMBio. Instituto Chico Mendes de Conservação da Biodiversidade. II Curso de Espeleologia e Licenciamento Ambiental. Belo Horizonte: ICMBio, 2010.

KERR, W. E.; CARVALHO, G. A.; DA SILVA, A. C.; ASSIS, M. G. $P$.. Aspectos poucos mencionados da biodiversidade amazônica. Parcerias Estratégicas. CEE MCT, v.12, n.2, p.2041, 2001.

MEDINA, B. M. O.; RIBEIRO, K. T.; SCARANO, F. R.. Plantplant and plant-topography interactions on a rock outcrop at high altitude in southeastern Brazil. Biotropica, v.38, n.1, p.1-7, 2006. DOI: http://doi.org.10.1744/j.17447429.2005.00105.x

MELLO, M. A. R.. Interações entre o morcego Carollia perspicillata (Linnaeus, 1758) (Chiroptera: Phyllostomidae) e plantas do gênero Piper (Linnaeus, 1737) (Piperales: Piperaceae) em uma área de Mata Atlântica. Dissertação (Mestrado em Biologia) - Universidade do Estado do Rio de Janeiro, Rio de Janeiro, 2002.

MULLER, M. F.; REIS, N. R.. Partição de Recursos Alimentares Entre Quatro Espécies de Morcegos Frugífvoros (CHIROPTERA, PHYLLOSTOMIDAE). Revista brasileira de Zoologia, v.9, n.3-4, p.345-355, 1992. DOI: https://doi.org/10.1590/S0101-81751992000200022

RAUNKIER, C.. Types biologiques pour la géographie botanique: Oversigt over Det Kongelige Danske Videnskabernes Selskabs Forhandlinger. 1905.

SOS MATA ATLÂNTICA. Atlas of forest remnants of the Mata Atlântica period 2016: final report. Vitória: The SOS, 2016

SILVA, C. V. V.; MATARAZZO, A.. Levantamento e Caracterização da Mastofauna Terrestre da Represa Billings, São Bernardo do Campo/SP. In: CONGRESSO NACIONAL DO MEIO AMBIENTE, 14. Anais. Poços de Caldas, 2017.

SILVA, C. V. V.; ALMEIDA, J. R.; SILVA, C. E.; CARVALHO, L. O.; SILVA, C. D.; RIGUEIRAL, L. H. G.; PAULA, R. G.. Structure and floristic survey of a forest fragment in the Billings Reservoir, São Paulo. Revista Ibero Americana de Ciências Ambientais, v.9, n.7, p.1-11, 2018. DOI: http://doi.org/10.6008/CBPC2179-6858.2018.007.0001 
VIEIRA, V. S.; SILVA, M. A.; CORRÊA, T. R.; LOPES, N. H. B. Mapa Geológico do Estado do Estado do Espírito Santo: Escala 1:400.000. CPRM, 2018.
VIEIRA, N. C.; CARVALHO, L. O.; SILVA, C. V. V.; ABREU, L. A. S.. A Importância das Operações de Manejo e Resgate de Fauna na Implantação de Empreendimentos Imobiliários no Bioma Mata Atlântica. In: SEMANA ACADÊMICA DE BIOLOGIA, 37. Anais. Seropédica: UFRRJ, 2017.

A CBPC - Companhia Brasileira de Produção Científica (CNPJ: 11.221.422/0001-03) detém os direitos materiais desta publicação. Os direitos referem-se à publicação do trabalho em qualquer parte do mundo, incluindo os direitos às renovações, expansões e disseminações da contribuição, bem como outros direitos subsidiários. Todos os trabalhos publicados eletronicamente poderão posteriormente ser publicados em coletâneas impressas sob coordenação da Sapientiae Publishing, da Companhia Brasileira de Produção Científica e seus parceiros autorizados. Os (as) autores (as) preservam os direitos autorais, mas não têm permissão para a publicação da contribuição em outro meio, impresso ou digital, em português ou em tradução. 